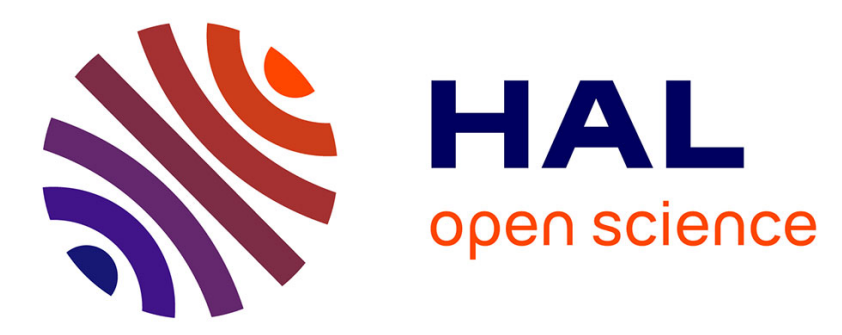

\title{
A Deep learning method for accurate and fast identification of coral reef fishes in underwater images
}

Sebastien Villon, David Mouillot, Marc Chaumont, Emily Darling, Gérard Subsol, Thomas Claverie, Sébastien Villéger

\section{To cite this version:}

Sebastien Villon, David Mouillot, Marc Chaumont, Emily Darling, Gérard Subsol, et al.. A Deep learning method for accurate and fast identification of coral reef fishes in underwater images. Ecological Informatics, 2018, 48, pp.238-244. 10.1016/j.ecoinf.2018.09.007 • lirmm-01884005

\section{HAL Id: lirmm-01884005 \\ https://hal-lirmm.ccsd.cnrs.fr/lirmm-01884005}

Submitted on 29 Sep 2018

HAL is a multi-disciplinary open access archive for the deposit and dissemination of scientific research documents, whether they are published or not. The documents may come from teaching and research institutions in France or abroad, or from public or private research centers.
L'archive ouverte pluridisciplinaire HAL, est destinée au dépôt et à la diffusion de documents scientifiques de niveau recherche, publiés ou non, émanant des établissements d'enseignement et de recherche français ou étrangers, des laboratoires publics ou privés. 


\title{
A Deep Learning method for accurate and fast identification of coral reef fishes in underwater images
}

5 Sébastien Villon ${ }^{\mathrm{a}, \mathrm{b}}$, David Mouillot ${ }^{\mathrm{a}, \mathrm{g}}$, Marc Chaumont ${ }^{\mathrm{b}, \mathrm{c}}$, Emily S. Darling ${ }^{\mathrm{d}, \mathrm{e}}$, Gérard Subsol ${ }^{\mathrm{b}}$, Thomas Claverie $^{\mathrm{a}, \mathrm{f}}$, Sébastien Villéger ${ }^{\mathrm{a}}$

villon@lirmm.fr

10

a MARBEC, University of Montpellier,CNRS, IRD, Ifremer, Montpellier, France

b LIRMM, University of Montpellier/CNRS, France

c University of Nîmes, Nîmes, France

d Department of Ecology and Evolutionary Biology, University of Toronto, Toronto, Canada

15 e Marine Program, Wildlife Conservation Society, Bronx, United States

f CUFR Mayotte, France

g Australian Research Council Centre of Excellence for Coral Reef Studies, James Cook University, Townsville, QLD 4811 Australia.

\begin{abstract}
Identifying and counting fish individuals on photos and videos is a crucial task to cost-effectively monitor marine biodiversity, yet it remains difficult and time-consuming. In this paper, we present a method to assist the identification of fish species on underwater images, and we compare our model performances to human ability in terms of speed and accuracy. We first tested the performance of a convolutional neural network (CNN) trained with different photographic databases while accounting for different post-processing decision rules to identify 20 fish species. Finally, we compared the performance of species identification of our best CNN model with that of humans on a test database of 1197 fish images representing nine species. The best CNN was the one trained with 900000 images including (i) whole fish bodies, (ii) partial fish bodies and (iii) the environment (e.g. reef bottom or water). The rate of correct identification was $94.9 \%$, greater than the rate of correct identification by humans (89.3\%). The CNN was also able to identify fish

35 individuals partially hidden behind corals or behind other fish and was more effective than humans to identify fish on smallest or blurry images while humans were better to identify fish individuals in unusual positions (e.g. twisted body). On average, each identification by our best CNN using a common hardware took 0.06 seconds. Deep Learning methods can thus perform efficient fish identification on underwater images and offer promises to build-up new video-based protocols for monitoring fish biodiversity cheaply and effectively.
\end{abstract}

Keywords: marine fishes, convolutional neural network, underwater pictures, machine learning, automated identification 


\section{Introduction}

Coral reefs host a massive and unique biodiversity with, for instance, more than 6,000 fish species (Mouillot et al., 2014) and provide key services to millions of people worldwide (Rogers et al., 50 2017). Yet, coral reefs are increasingly impacted by global warming, pollution and overfishing (Graham et al., 2011; Robinson et al., 2017; Scott and Dixson, 2016; Hughes et al., 2017; Cinner et al. 2018). The monitoring of fish biodiversity through space and time on coral reefs (Halpem et al., 2008; Jackson et al., 2001) is thus a critical challenge in marine ecology in order to better understand the dynamics of these ecosystems, predict fisheries productivity for dependent human

55 communities, and improve conservation and management strategies to ensure their sustainability (Krueck et al., 2017; Pandolfi et al., 2003).

Most surveys of coral reef fishes are based on underwater visual censuses (UVC) carried out by scuba divers (Brock, 1954; Cinner et al., 2016, 2018; Thresher and Gunn, 1986). While non-

60 destructive, this protocol requires the identification and enumeration of hundreds of individuals belonging to hundreds of species so it can only be performed by highly trained scientific divers while being time consuming. In addition, the accuracy of such visual-based assessments is highly dependent on conditions (depth, dive duration) and divers experience while the presence of diver biases the detection of some furtive species (Chapman and Atkinson, 1986; Harvey et al., 2004;

65 Sale and Sharp, 1983; Watson and Harvey, 2007; Willis, 2001).

Over the last decade, underwater cameras have been increasingly used to record fish individuals on fixed videos, along belt transects (Cappo, 2003; Langlois et al., 2010; Mallet and Pelletier, 2014), or around baits to attract predators (Harvey et al., 2007; Watson et al., 2005; Willis and Babcock,

70 2000). Video-based surveys provide estimations of fish abundance and species diversity similar to UVC-based surveys (Pelletier et al., 2011). Video-based methods can be used to overcome the limitations of human-based surveys (depth, time underwater). They also provide a permanent record that could later be re-analyzed. However, assessing fish biodiversity and abundance from videos requires annotation by highly trained specialists and is a demanding, time-consuming and expensive

75 task with up to several hours required to identify fish individuals per hour of video (Francour et al. 1999). There is thus an urgent need to develop new tools for automatic identification of fish individuals on photos and videos to provide accurate, efficient, repeatable and cost-effective monitoring of reef ecosystems.

80 Automatic and accurate identification of organisms on photos is crucial to move toward automatic video processing. In addition, automatic identification of species on photos is especially relevant for citizen science. For instance, the application pl@ntNet (https://plantnet.org/) automatized the identification of 13,000 species of plants. For fishes, some public tools like inaturalist.org or fishpix (http://fishpix.kahaku.go.jp) offer the possibility to upload images that will be manually identified

85 by experts. These valuable initiatives would benefit from the support of automatic identification algorithms to save time of experts.

The performance of recent methods dedicated to the automatic identification of objects on images has drastically increased over the last decade (Siddiqui et al, 2017; Lowe, 1999). However, some of

90 these methods have been tested only on images recorded in standardized conditions, in terms of light and/or fish position (e.g. only lateral views) (Levi, 2008; Alsmadi et al, 2010). Identification of fish individuals on 'real-life' underwater images is more challenging because $(i)$ color and brightness are highly variable between images and even within a given image, (ii) the environment is textured and has a complex 3-dimentional architecture, (iii) fish can be recorded in various

95 positions and are often hidden behind other fish or corals, and (iv) the acquisition camera and its internal parameters can be variable. 
Recently, an accurate automation of detection and identification of fish individuals has been 100 obtained (Shortis et al., 2016) using machine-learning methods such as support vectors machines (Blanc et al. 2014), nearest neighbor classifiers (Levi, 2008), discriminant analysis classifiers (Spampinato et al., 2010) or Deep Learning (Li et al., 2015). The latest competitions (Joly et al., 2106) and comparisons (Villon et al., 2016) show that Deep Learning based methods, which are a type of neural network combining simultaneously automatic image descriptor and descriptor

105 classification, tend to achieve the highest performance, particularly convolutional neural network (CNN) that add deep layers to classical neural networks (Lecun et al., 2015).

However, the accuracy of CNN methods is highly dependent on the extent and the quality of data used during the training phase, i.e. the set of images annotated by experts for all classes to identify.

110 The effects of the extent of the training database (i.e. the number of images per class) and associated post-processing decision rules on the performance of the whole identification process remain untested. Since real-life videos of coral reef fishes and thus images extracted from those videos are highly diverse in terms of surrounding conditions (environment, light, contrast) and fish positions, the performance of identification methods must be carefully tested using an independent

115 dataset to assess its robustness over changing conditions.

Furthermore, the performance of models should be compared to the performance of humans to determine whether machine-based assessment of fish biodiversity provides an advantage over traditional human processing of images (Matabos et al., 2017). Here we tested the performance of 4

120 models, built with the same CNN architecture, for automatic identification of fish species on coral reefs. Specifically, we assessed the effect of several training image datasets and several decision rules, with a particular focus to identify fish partially hidden behind the coral habitat. We then compared the performances of the best CNN models to those of humans.

\section{Methods}

\section{Image acquisition for training and testing $\mathrm{CNN}$ models}

We used GoPro Hero3+ black and GoPro Hero4+ black cameras to record videos at 30 fps over 50 130 reef sites around the Mayotte island (Mozambique Channel, Western Indian Ocean) including fringing and barrier reefs, and at depth from 1 to $25 \mathrm{~m}$. Videos were recorded from April to November 2015. Recording conditions varied between sites and days, especially in term of light and environment (i.e. proportion of hard and soft corals, sand and water visible). All videos were recorded with a resolution of 1280x720 (HD) and 1920x1080 pixels (full HD) with default settings

135 for color temperature and exposure (i.e. no use of protune or automatic color balance adjustment).

For all recordings, the cameras remained stationary and no artificial light or filter were used. We recorded 116 videos representing a total of 25 hours.

For all videos, 5 frames per second were extracted leading to a database of 450,000 frames. Fish

140 individuals were delineated and identified by undergraduate, master degree students and $\mathrm{PhD}$ students in marine biology trained for fish identification on videos with the support of identification keys and under the supervision of experts (Froese and Pauly, 2000; Taquet and Diringer, 2007). Each annotation consisted in drawing a rectangle bounding box around a single fish individual, including only its very close context as illustrated on Fig.1.a, and associating a label (i.e. species

145 name) to this individual. We call those specific images "thumbnails".

The criteria for the annotation were:

1) Annotate a fish only if there is no more than $10 \%$ of its surface covered by another object (fish, coral, or substrate). 
Draft Version - Accepted in Elsevier Ecological Informatics the $3^{\text {th }}$ of September 2018

2) Annotate a fish only if it can be identified at the species level in the frame (i.e. independently 150 from previous or next frames where the same fish could have a better position for identification).

3) Annotate a fish only if its apparent size is larger than 3,000 squared pixels, i.e. ignoring fish individuals too far from the camera.

4) Annotate images from different habitats and depths to represent a broad range of light conditions and environment, and target at least 1,200 thumbnails per species.

We did not consider thumbnails of individuals in positions where they are hard to identify (such as fish seen from front) since they would bring more noise than relevant information for the algortihm as the discriminating parts of the fish are hidden (specific color pattern, marks, etc). We did not process the image with background subtraction for 2 reasons:

160 1) We did assume that in our case the context helps to identify fish species, as some species tend to be associated with some particular environment such as Amphiprion in sea anemone, Chromis viridis on Acroporas, Caesionidae in plain water etc...

2) We wanted our process to be used on full images. In such context, separating fish individuals from their background would be either manual or not reliable.

This annotation procedure yielded a training dataset (T0) with 44,625 annotated fish thumbnails belonging to 20 species (Table 1). The 20 species present in the training dataset represent the most common species appearing in the videos and belong to 12 families among the most diverse and abundant on coral reefs worldwide (e.g. Pomacentridae, Acanthuridae, Chaetodontidae, Labridae).

170 Models were then tested using a set of images independent from the ones used for the training phase to ensure a cross validation procedure and that model performance reflects real-life study case. More specifically, the test dataset was built using 6 videos recorded in contexts different from those of videos used for training (i.e. sites or days not included in the training database). Annotations of these videos were made like the training dataset except that it included fish individuals partially

175 hidden by other fish or by corals as well as fish individuals viewed from front or back (their identity being checked using when necessary previous or next frames). As our goal is to identify fish species on images and photos, the test without any filter allows to assess to which extent our algorithm is performing to help users to take a picture good enough for fish identification.

180 We obtained a test dataset of 4,405 annotated fish thumbnails belonging to 18 out of the 20 species present in the training dataset (Table S3). We then randomly selected a subset of 1,197 fish thumbnails belonging to 9 species to compare the performance of humans vs. obtained models (Table S3).

\section{Deep-learning algorithm}

We used a convolutional neural network $(\mathrm{CNN})$ architecture to build a fish identification model (Schmidhuber, 2015). CNNs are a class of deep learning algorithms used to analyze data and particularly to classify objects from images (Krizhevsky et al., 2012).

CNNs are made of layers of interconnected neurons and each neuron includes a 'convolutional kernel' that computes a set of mathematical operations (defined by 'weights') on the matrices of values describing the image (i.e. values for each color channel for each pixel).

Convolutional features are combinations of pixel values that encode information about target

195 classes. Low level features can detect edges or color patterns, while, high level features might differentiate different fish shapes.

This process yielded 'feature maps', i.e. a vector describing image characteristics (shapes, colors, statistical information of the image). 
Draft Version - Accepted in Elsevier Ecological Informatics the $3^{\text {th }}$ of September 2018

200 The main difference between CNNs and other classifiers is that CNNs build the "feature extractors" (convolutions in the case of $\mathrm{CNN}$ ) and the classifier conjointly.

Then the last layer of the network classifies those feature maps with a soft-max method and gives as output scores corresponding to the "probability" that each image belongs to each of the learned classes (Lecun et al., 2015). More precisely, the training phase of the network consists in iteratively

205 modifying the weights of the convolutional kernels (hence features maps) to optimize the classification score of all classes.

We used a GoogLeNet architecture as it was the winner of the 2015 competition imageNet (Szegedy et al., 2015), an identification challenge on 1,000 different classes. This CNN is composed of 22

210 layers. It uses inception modules. Inception modules allow the network to use convolutions of different sizes $(1 * 1,3 * 3$ and $5 * 5$ pixels) and to weight each of these convolutions. This network could thus account more or less strongly for the context of each pixel, which increases the range of possibilities to improve its performance during the training.

215 A link to a depository with architecture details is given at the end of references. We stopped the network training after 70 epochs (i.e. a complete scope of the dataset where each image is used only once), to prevent overfitting. We used a learning rate of $10^{-5}$, an exponential learning decay with a Gamma of 0.95 , a dropout of $50 \%$ and an Adam Solver type as learning parameters. Those are classic hyper-parameters for a fast convergence of the network without over-fitting (Srivastava,

220 2014). The weight initialization is also classic with a random Gaussian initialization. The training lasted 8 days on our configuration; we trained and ran our code on a computer with 64GB of RAM, an i7 3.50GHz CPU and a Titan X GPU card for 900,000 images.

We used at least 2200 thumbnails per fish species class, and batches of 16 images to train our

225 network. We ran this architecture on Caffe (Jia et al, 2014). To focus on the impact of the training data, we used the same CNN architecture for our training and test procedures.

\section{Building the training datasets}

Using the raw training dataset of 20 fish species (Table S1) we built 4 different datasets to assess the influence of the dataset building on classification results (Table S2).

The first training dataset T1 contained raw fish thumbnails (T0) and their respective mirror images. More precisely, we doubled the number of thumbnails per fish individual by flipping each thumbnail with respect to the vertical axis. Such a procedure homogenizes the proportion of left-

235 oriented and right-oriented individuals in the database and we hypothesize it could improve the average identification rate since fish individuals are seen in all positions.

The second training dataset T2 contained fish thumbnails from T1 plus "part of fish" thumbnails. Thumbnails of this class were obtained by splitting each thumbnail of T0 into 4 parts: upper part,

240 lower part, right part, and left part as shown on Fig.1. b. We hypothesized that this class can prevent from misidentification of partially hidden individuals. For instance, if a black and white fish is partially hidden so that only its dark part is visible it would likely be confounded with a full dark fish.

245 The third training dataset T3 contained fish thumbnails from T2 plus thumbnails of a single class "Environment". Environment thumbnails were extracted at random in portion of frames where no fish was detected. We hypothesized that such a procedure can help distinguishing between fish species given the high diversity of environments present around them, i.e. allowing CNN models to find more efficiently features discriminating fishes whatever the background around them. 
Draft Version - Accepted in Elsevier Ecological Informatics the $3^{\text {th }}$ of September 2018

The fourth training dataset T4 contained thumbnails from T3 minus the "part of fish", which is replaced by 20 classes "part of species" obtained by splitting thumbnails from each species. The difference between T3 and T4 was that T3 contained only one global class "part of fish" whereas T4 contained as many "part of species" classes as there were "fish" species.

Figure 1: Thumbnails samples.

a) Examples of thumbnails of whole fish individuals from the training database and b) examples of thumbnails extracted from whole fish picture to build "part of fish" and "part of species" classes.

a)

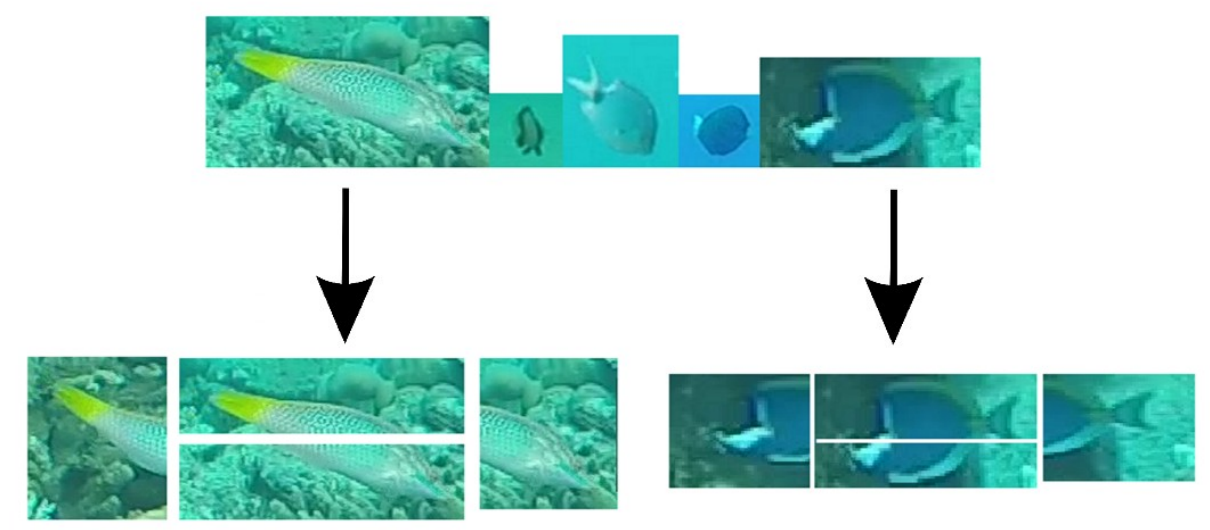

b)

\section{Testing the performance of models}

We first compared the performance of the 4 models trained using each of the 4 training datasets. In addition, we tested the performance of models after correcting their raw outputs using two $a$ posteriori decision rules. First, since the networks trained with T2, T3 or T4 are likely to recognize environment samples with a high confidence score (over 99\%) they could thus classify some fish as an environment class (i.e. false positive). We therefore defined a decision rule (r1): when the first proposition of the network was 'environment' with a confidence lower than $99 \%$ we provide, as

270 final output, the fish class with the highest probability.

Similarly, as "part of species" classes present in T4 were just a methodological choice to improve model performance (and hence were absent from the test database), we defined a second decision rule (r2): when the result given by the network is "part of species X", we provide, as final output, "species X".

We then compared the performance of the best model with the performance of humans, in terms of accuracy and time needed to identify fish thumbnails. This experiment aimed to compare the results obtained by humans to those obtained by the CNN using a fair method. This means that during the comparison procedure both $\mathrm{CNN}$ and humans were shown thumbnails without any contextual information (there was no general view of the scene), and the thumbnails were never seen before the test procedure. The procedure could even be slightly in favor of humans because they knew that there were only 9 species to classify, whereas the CNN worked from the 21 species learned and misclassification could occur with a higher probability.

285 Our goal was to allow humans to identify species as fast as possible in this particular context. For this purpose, we developed an online survey tool operating in Chrome web browser which allowed users to easily and quickly identify a fish on a picture displayed at the center of the window by either writing the name of the species (with auto-completion) or to select it from a list. A "help" 
Draft Version - Accepted in Elsevier Ecological Informatics the $3^{\text {th }}$ of September 2018

sheet showing a reference picture of the fish species to identify was available in the same window

290 (Fig. S1). Once a user selected a species, time to perform the identification was saved and a new randomly chosen fish picture was displayed.

This comparison was performed on 1197 randomly chosen thumbnails of only 9 species present in the test thumbnail dataset (Table S3) to ease the test for humans. The test lasted 20 minutes with the

295 help of 10 undergraduate students, 2 Master Degree and $2 \mathrm{PhD}$ student in biology from the University of Montpellier who were previously trained to identify these fish species. Such a short test duration for humans reduces tiredness that could decrease identification accuracy and rapidity. We then compared the answers to the ground truth (i.e. identification made by experts in fish taxonomy) and computed the time needed to perform each identification. We finally compared correct identification rate and time per fish individual between humans and the best CNN model.

\section{Results}

Influence of the training database and of post-processing on model performance

305 The $4 \mathrm{CNN}$ models obtained with 4 different datasets (T1, T2, T3, T4) had similar mean identification success rate, close to $87 \%$ (Table 1). However, there were marked differences in correct identification rate between models for several species. For instance, Dascyllus carneus was correctly identified in only $4 \%$ of the cases by model trained with only whole fish thumbnails (T1) while it was correctly identified in more than $90 \%$ of cases by the three other models. Conversely,

310 Pomacentus sulfureus was more often correctly identified by the models trained with T1 than by models trained with environment thumbnails (T3 and T4).

Table 1:

Raw success rate (\%) of the $4 \mathrm{CNN}$ models trained with different thumbnails datasets for 315 identifying 18 fish species. See details about training databases in Table S2.

\begin{tabular}{|c|c|c|c|c|}
\hline Species & Only whole fish (T1) & $\begin{array}{l}\text { Whole fish and part of fish } \\
\text { (T2) }\end{array}$ & $\begin{array}{l}\text { Whole fish, environment } \\
\text { and part of fish (T3) }\end{array}$ & $\begin{array}{l}\text { Whole fish, environment } \\
\text { and part of species (T4) }\end{array}$ \\
\hline Abudefduf sparoides & 80.8 & 94.9 & 85.8 & 82.8 \\
\hline Abudefduf vaigiensis & 94.5 & 89.0 & 89.0 & 80.0 \\
\hline Chaetodon trifascialis & 94.7 & 90.4 & 91.0 & 85.1 \\
\hline Chromis weberi & 98.8 & 96.6 & 92.9 & 98.8 \\
\hline Dascyllus carneus & 4.0 & 91.5 & 92.3 & 91.5 \\
\hline Monotaxis grandoculis & 90.0 & 68.0 & 77.7 & 79.1 \\
\hline Myripristis botche & 100 & 80.0 & 75.0 & 95.0 \\
\hline Naso elegans & 96.2 & 92.4 & 89.7 & 95.1 \\
\hline Naso vlamingii & 92.6 & 95.3 & 89.1 & 95.8 \\
\hline Nemateleotris magnifica & 100 & 98.2 & 99.5 & 99.1 \\
\hline Odonus niger & 79.5 & 91.4 & 92.6 & 81.8 \\
\hline Plectroglyphidodon lacrymatus & 100 & 100 & 74.2 & 94.0 \\
\hline Pomacentrus sulfureus & 97.8 & 67.6 & 82.5 & 73.8 \\
\hline Pterocaesio tile & 100 & 100 & 100 & 99.5 \\
\hline Pygoplytes diacanthus & 84.2 & 91.5 & 84.2 & 86.8 \\
\hline Thalassoma hardwicke & 83.9 & 82.7 & 88.0 & 87.3 \\
\hline Zanclus cornutus & 93.3 & 84.3 & 86.4 & 89.0 \\
\hline Zebrasoma scopas & 89.0 & 88.8 & 88.8 & 92.7 \\
\hline $\begin{array}{l}\text { Mean identification success } \\
\text { rate }\end{array}$ & 87.6 & 87.9 & 87.7 & 86.9 \\
\hline
\end{tabular}


Post-processing raw outputs of the model T4 following decision rule r1 (i.e. environment not considered as a correct result), improved correct identification rate from 86.9 to $90.2 \%$ (Table 2).

Adding decision rule $\mathrm{r} 2$ (i.e. identification of a part of a species considered as a correct answer) increased this success rate to $94.1 \%$ (Table 2). Hence, post-processing raw outputs of the model trained with the most complete dataset provided the best identification rate. Among the 18 species, success rate ranged from 85.2 to $100 \%$, with only 3 species being correctly identified in less than

$32590 \%$ of cases and 9 species being correctly identified in more than $95 \%$ of cases, including 3 with a correct identification rate $>99 \%$.

Confusions between 2 fish species were lower than 4\% (Table 3). Confusion between a fish and the environment was common when no post-processing was applied with for instance up to $20.9 \%$ of

330 Pomacentrus sulfureus individuals misidentified as environment (Tables S4, S5). However, applying decision rule $\mathrm{r} 1$ decreased this error rate to less than $4 \%$ (Table 3 ).

Table 2:

Success rate (\%) of $3 \mathrm{CNN}$ models for identifying 18 fish species. First column presents accuracy 335 based on raw output of a deep-learning model trained with thumbnails of whole fish, part of species and environment (as last column of Table 2). Second column presents accuracy after applying a decision rule ' $r 1$ ' keeping most likely fish class if 'environment' was the most likely class. Third column presents results after applying decision rule ' $r 1$ ' plus decision rule ' $\mathrm{r} 2$ ': "part of species $\mathrm{X}$ " is equivalent to "species $\mathrm{X}$ ". Numbers are percentages of correct fish identification.

$$
\text { Species }
$$

Abudefduf sparoides

Abudefduf vaigiensis

Chaetodon trifascialis

Chromis weberi

Dascyllus carneus

Monotaxis grandoculis

Myripristis botche

Naso elegans

Naso vlamingii

Nemateleotris magnifica

Odonus niger

Plectroglyphidodon lacrymatus

Pomacentrus sulfureus

Pterocaesio tile

Pygoplytes diacanthus

Thalassoma hardwicke

Zanclus cornutus

Zebrasoma scopas

Average success rate
Raw output

82

80

85.1

98.8

91.5

79.1

95

95.1

95.8

99.1

81.8

94

73.7

99.5

86.8

87.3

89

92.7
Decision Rule r1

88

89

87.8

98.8

91.5

83.3

95

96.7

96

100

81.8

94

78.1

100

89.4

89.6

95.3

92.7
Decision Rules r1 and r2

91.9

98

91.5

99.2

91.5

86.1

95

97.8

96

100

85.2

96

87.9

100

92.1

94.2

98.4

92.7

86.9

90.2

94.1 
Table 3:

Performance and confusion rates of CNN model for 9 fish species. The CNN was trained with

345 dataset T4 (see Table 1), including thumbnails of whole fish, part of species and environment. Raw CNN outputs were post-processed with following decision rules:

' $r 1$ ': If the highest probability is lower than $99 \%$ and is for class "environment" then the fish class with the second highest probability is kept.

'r2': Outputs "part of species X" are considered as equivalent to "species X" (i.e. the scores of $A$.

350 sparoides and part of $A$. sparoides were merged).

Columns indicate the species to classify, and rows indicate the results (most probable species) given by the model (i.e. percentages on the diagonal indicate success rate). Only values over $1 \%$ are shown. Full names of species are in Table 1

\begin{tabular}{|c|c|c|c|c|c|c|c|c|c|}
\hline Species & A.sparoides & A. vaigiensis & C. Trifascialis & N. elegans & P. sulfureus & P. diacanthus & T. hardwicke & Z. cornutus & Z. scopas \\
\hline A.sparoides & 91.9 & & & & & & 1.3 & & \\
\hline A. vaigiensis & 1.1 & 98.2 & & & & & & & \\
\hline C. Trifascialis & & & 91.5 & & & & 1.0 & & \\
\hline C. Weberi & 2.2 & & & & & & 1.1 & 1.5 & \\
\hline $\begin{array}{l}\text { D. caruleus } \\
\text { N. elegans }\end{array}$ & & & & 97.8 & & & & & 3.9 \\
\hline $\begin{array}{l}\text { P. sulfureus } \\
\text { P disthen }\end{array}$ & 1.0 & 1.8 & 1.0 & & 87.9 & 2.5 & & & \\
\hline $\begin{array}{l}\text { P. diacanthus } \\
\text { P. lacrymatus }\end{array}$ & & & & & & $\begin{array}{c}92.1 \\
2.6\end{array}$ & & & \\
\hline T. Hardwicke & 2.0 & & 1.5 & & & & 94.2 & & \\
\hline $\begin{array}{l}\text { Z. cornutus } \\
Z \text {. scopas }\end{array}$ & 1.0 & & & & & & & 98.5 & 927 \\
\hline Environment & & & & & 3.6 & 2.6 & & & 1.0 \\
\hline
\end{tabular}

\section{Performance of CNN models vs. humans}

360 On average, each human identified 270 fish thumbnails during the 20-minute test. Mean rate of correct classification for humans was of $89.3 \%$ with a standard deviation of $6 \%$ (Table 4 ). Rate of correct classification achieved by the best model on the same thumbnails was of $94.9 \%$ with a standard deviation of $3.3 \%$. Correct classification rate by the best model ranged from $88.2 \%$ (Abudefduf sparoides) to 98.2\% (Abudefduf vaigiensis). For only one species (Zanclus cornutus),

365 the best model had a lower performance than humans but both were higher than $97 \%$. The mean time needed to identify a fish by humans was 5 seconds, with the fastest answer given in 2 seconds and the longest in 9 seconds. On average, each classification by our final model took 0.06 seconds with hardware detailed above.

When tested against humans using a challenge with only 9 potential species, the network was more

370 effective on smaller or blurrier thumbnails, while humans were better to recognize unusual positions (Fig. 2). There were only $2 \%$ of fish individuals which were neither identified by humans nor by the network (Fig. 2).

However, experts with more than 10 years of experience in the field may have outperformed the CNN model in terms of correct identification particularly for hidden or unusually positioned fish. 
Draft Version - Accepted in Elsevier Ecological Informatics the $3^{\text {th }}$ of September 2018

Table 4: Accuracy (success rate in \%) of fish identification by humans and by the best CNN model for 9 species. The model was trained using thumbnails of whole fish, part of fish species and 380 environment (T?). Raw outputs were post-processed applying two decision rules: (r1) keeping most likely fish class if "environment" was the most likely class, and (r2) considering "part of species X" equivalent to "species X".

\begin{tabular}{cccc}
\hline Species & Number of thumbnails tested & Deep-learning model & Humans \\
Abudefduf sparoides & 88 & 93.4 & 87.7 \\
Abudefduf vaigiensis & 47 & 97.3 & 84.7 \\
Chaetodon trifascialis & 149 & 95.1 & 89.4 \\
Naso elegans & 165 & 98.4 & 94.8 \\
Pomacentrus sulfureus & 443 & 97.9 & 93.2 \\
Pygoplites diacanthus & 35 & 90.4 & 77.4 \\
Thalassoma hardwicke & 73 & 96 & 91 \\
Zanclus cornutus & 53 & 97.1 & 97.8 \\
Zebrasoma scopas & 144 & 96.2 & 88.3 \\
\hline Average success rate & 1197 & 95.7 & 89.3 \\
\hline
\end{tabular}

\section{Discussion}

Assessing the performance of the same CNN trained with four different datasets demonstrates that correct identification rates were all close to $87 \%$. Thus, a training dataset made of more than 1300 thumbnails of each species could yield a success rate similar to the ones obtained in image identification challenges in more controlled conditions (Siddiqui et al., 2017). Beyond their number, thumbnails of each species used to train the network were extracted from different videos and different sites to include as many orientations of fish as possible and to embrace a strong environmental variability in terms of light, colors and depth. However, our best CNN model may perform more poorly with a broader range of species across other locations and environments. Our 18 species belong to 12 different families so are likely to differ in shape or color. With much more congeneric species these differences would make the identification much more challenging.

400 Despite a similar mean success rate, the performance of the four models differed markedly for some species. Ten out of the 18 species were more often correctly identified when CNN models were trained using thumbnails of part of fish or environment, and eight other species were better identified by the model trained with only whole fish picture. Additionally, some species were often misidentified as environment (Table S5), even if the probability of this class was lower than

$40599 \%$.Such confusion could be explained by the fact that some small species are always close to corals and of similar colors, e.g. the yellow benthic fish Pomacentrus sulfureus. Similarly, for the small Dascyllus carneus case, which is often misclassified with almost all fish species when background was not included in the training dataset, the addition of environment thumbnails certainly helps the network to focus on features unique to the fish body rather than to its 410 surrounding.

We demonstrate that the best results were obtained after applying two a posteriori decision rules on raw outputs from the neural network trained with the most complete set of thumbnails. This model 
Draft Version - Accepted in Elsevier Ecological Informatics the $3^{\text {th }}$ of September 2018

reached a success rate of $94.1 \%$ for the 18 species tested, with only 3 species being correctly 415 identified in less than $90 \%$ of cases. Therefore, training a neural network with thumbnails from surrounding environment and thumbnails of part of each fish species is important to reach a high correct identification rate in real-life cases. The class "Environment" adds versatility to the training and hence helps the network to select features that are robust to the context around fish. Including classes "part of species" allows the network to classify correctly individuals partially hidden by

420 other fish or corals. Such situations were common in the test dataset as illustrated by the fact that up to $9 \%$ of individuals of Abudefduf vaigiensis were classified as "part of A. vaigensis" rather than "whole A. vaigensis".

The success rate of the best model is similar to that of the model of Siddiqui et al. (2016) which reached a success rate of $94.3 \%$ on 16 species. This latter model was trained on a much smaller training dataset of 1309 thumbnails than our model (>900 000 thumbnails). However, Siddiqui's model was designed to identify fish on videos recorded in partially controlled conditions (i.e. fish swimming close to a baited camera) while in our case we tested the ability of the model to identify fish partially hidden by corals as well as shot in all positions and orientations. The few

430 misidentifications by our best model mostly occurred when only the face or back of fish was visible. Such an issue could be easily circumvented in practice when analyzing videos because it is likely that each fish will be seen from the side on at least one frame (out of the 25 frames recorded per second by most cameras).

Figure 2: Samples of thumbnails recognized by the CNN model and not recognized by humans (a), samples of thumbnails recognized by humans and not recognized by the CNN model (b) and sample of thumbnails misidentified by both humans and the $\mathrm{CNN}$ model (c).

a)

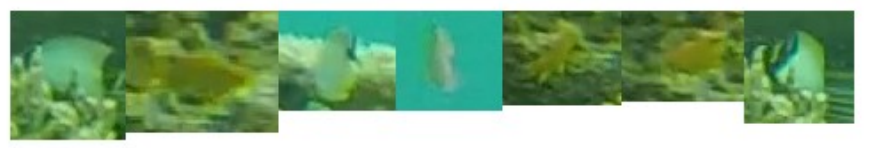

b)

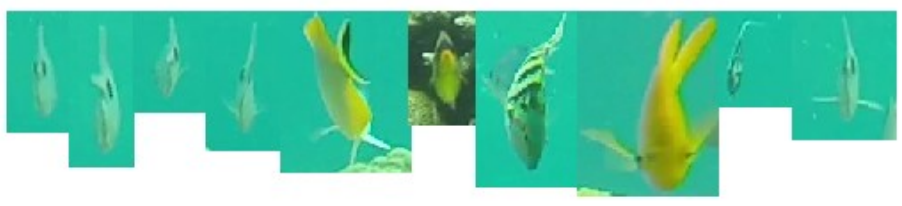

c)

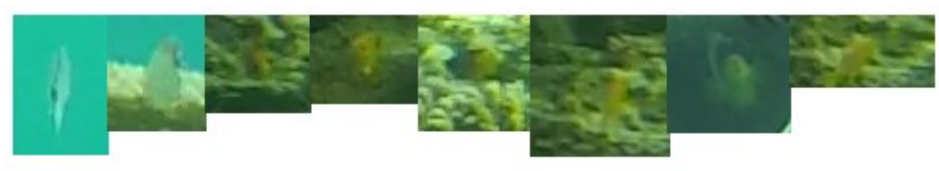




\section{Draft Version - Accepted in Elsevier Ecological Informatics the $3^{\text {th }}$ of September 2018}

Identification methods such as the ones presented here pave the way towards new ecological applications. First, such methods can work continuously and their performance is constant through time and hence reproducible, contrary to human experts who work discontinuously and are likely to 445 perform differently through time. Given the high rate of correct identifications, the best model could be used to pre-process a massive number of thumbnails: up to 1 million thumbnails per day. Furthermore, additional post processing procedures could be used. For example, under a certain threshold (e.g. 98\% certainty), human experts could be asked to check the thumbnails identified by CNN models. Such a two-step workflow would ensure a very high identification rate while saving

450 time of experts in fish taxonomy who will not have to identify "obvious" fish that can be accuratly identified by models. In addition, identification methods could also be used as a tool to initiate citizen science programs, for example where divers upload images of fish and obtain the most likely taxonomic identification from a CNN model. Therefore, the continued development of these identification tools could potentially offer benefits for both professional scientists collecting

455 massive raw data from the field, and for citizens to improve their awareness and knowledge about biodiversity (e.g. Bradley et al., 2017)

The method tested here is one step towards the identification of hundreds or thousands of fish species that occur on coral reefs (Kulbicki et al., 2013). Since the performance of CNNs is known to

460 increase with the number of classes (i.e. the 1000 classes of ImageNet) (Krizhevsky et al., 2012), there is no theoretical limit to such upscaling, the main challenge being to increase the size of the training dataset and the computer power. However, the identification of rare species will remain challenge given the difficulty to collect enough thumbnails of such species in different conditions to train the model. Future work is also needed to broaden the range of conditions where the model is

465 efficient for most of species. In this paper, we considered only fixed videos recorded between $1 \mathrm{~m}$ and $25 \mathrm{~m}$ for both our training and testing datasets. It would relevant to include deeper videos as well as videos recorded with other protocols (e.g. baited remote underwater videos, transects).

Ultimately, the goal of automatic identification is not only to classify fish into species, but also to

470 localize and count them, and estimate their size (body length) on videos. The detection task in underwater videos remains challenging as the context is particularly complex. Towards this aim, including "environment" and "part of species" classes in the training of models will enhance the accurate detection of fish inidividuals partially hidden behind corals or other fish, for instance using a sliding windows approach over a video frame. We could also associate a classifier with a detector

475 (Weinstein et al., 2015, Price Tack et al, 2016). Such algorithms focus on the detection of objects of interest (such as fish individuals) in images. Ultimately, deep-learning based methods could help marine ecologists to develop new video-based protocols for a massive monitoring of increasingly imperiled reef fish biodiversity, in the same way as next-generation sequencing of DNA has revolutionized several research domains including biodiversity monitoring (Deiner et al., 2017).

\section{Acknowledgement}

We want to thank the CEMEB Label of Excellency of Montpellier for funding this work. 


\section{References}

Alsmadi, M. K., Omar, K. B., Noah, S. A., \& Almarashdeh, I. (2010). Fish recognition based on robust features extraction from size and shape measurements using neural network. Journal of

490 Computer Science, 6(10), 1088.

Blanc, K., Lingrand, D., \& Precioso, F. (2014, November). Fish species recognition from video using SVM classifier. In Proceedings of the 3rd ACM International Workshop on Multimedia Analysis for Ecological Data (pp. 1-6). ACM.

Bradley M. Norman, Jason A. Holmberg, Zaven Arzoumanian, Samantha D. Reynolds, Rory P.

495 Wilson, Dani Rob, Simon J. Pierce, Adrian C. Gleiss, Rafael de la Parra, Beatriz Galvan, Deni Ramirez-Macias, David Robinson, Steve Fox, Rachel Graham, David Rowat, Matthew Potenski, Marie Levine, Jennifer A. Mckinney, Eric Hoffmayer, Alistair D. M. Dove, Robert Hueter, Alessandro Ponzo, Gonzalo Araujo, Elson Aca, David David, Richard Rees, Alan Duncan, Christoph A. Rohner, Clare E. M. Prebble, Alex Hearn, David Acuna, Michael L. Berumen,

500 Abraham Vázquez, Jonathan Green, Steffen S. Bach, Jennifer V. Schmidt, Stephen J. Beatty, David L. Morgan; Undersea Constellations: The Global Biology of an Endangered Marine Megavertebrate Further Informed through Citizen Science, 2017/11/29, BioScience, bix 127.

Brock, V. E. (1954). A preliminary report on a method of estimating reef fish populations. The Journal of Wildlife Management, 18(3), 297-308.

505 Cappo, M., Harvey, E., Malcolm, H., \& Speare, P. (2003). Potential of video techniques to monitor diversity, abundance and size of fish in studies of marine protected areas. Aquatic Protected Areaswhat works best and how do we know, 455-464.

Chapman, C.J. \& Atkinson, R.J.A. (1986). Fish behaviour in relation to divers. Prog Underw Sci, $11,1-14$.

510 Cinner, J. E., Huchery, C., MacNeil, M. A., Graham, N. A., McClanahan, T. R., Maina, J., ... \& Allison, E. H. (2016). Bright spots among the world's coral reefs. Nature, 535(7612), 416.

Cinner, J. E., Maire, E., Huchery, C., MacNeil, M. A., Graham, N. A., Mora, C., ... \& D’Agata, S. (2018). Gravity of human impacts mediates coral reef conservation gains. Proceedings of the National Academy of Sciences, 201708001.

515 Deiner, K., Bik, H. M., Mächler, E., Seymour, M., Lacoursière-Roussel, A., Altermatt, F., ... \& Pfrender, M. E. (2017). Environmental DNA metabarcoding: Transforming how we survey animal and plant communities. Molecular ecology,26(21), 5872-5895.

Francour, P., Liret, C. \& Harvey, E. (1999). Comparison of fish abundance estimates made by remote underwater video and visual census. Naturalista sicil, 23, 155-168.

520 Froese, R., \& Pauly, D. (Eds.). (2000). FishBase 2000: Concepts Designs and Data Sources(Vol. 1594). WorldFish

Graham, N. A., Chabanet, P., Evans, R. D., Jennings, S., Letourneur, Y., Aaron MacNeil, M., ... \& Wilson, S. K. (2011). Extinction vulnerability of coral reef fishes. Ecology Letters, 14(4), 341-348.

Halpern, B. S., Walbridge, S., Selkoe, K. A., Kappel, C. V., Micheli, F., D'agrosa, C., ... \& Fujita, R. 525 (2008). A global map of human impact on marine ecosystems. Science, 319(5865), 948-952.

Harvey, E., Fletcher, D., Shortis, M. R., \& Kendrick, G. A. (2004). A comparison of underwater visual distance estimates made by scuba divers and a stereo-video system: implications for underwater visual census of reef fish abundance. Marine and Freshwater Research, 55(6), 573-580.

Harvey, E.S., Cappo, M., Butler, J., Hall, N. \& Kendrick, G. (2007). Bait attraction affects the

530 performance of remote underwater video stations in assessment of demersal fish community structure. Mar. Ecol. Prog. Ser., 350, 245-254

Hughes, T. P., Barnes, M. L., Bellwood, D. R., Cinner, J. E., Cumming, G. S., Jackson, J. B., ... \& Palumbi, S. R. (2017). Coral reefs in the Anthropocene. Nature, 546(7656), 82.

Jackson, J. B., Kirby, M. X., Berger, W. H., Bjorndal, K. A., Botsford, L. W., Bourque, B. J., ... \&

535 Hughes, T. P. (2001). Historical overfishing and the recent collapse of coastal ecosystems. Science, 293(5530), 629-637. 
Draft Version - Accepted in Elsevier Ecological Informatics the $3^{\text {th }}$ of September 2018

Javed, O., \& Shah, M. (2002, May). Tracking and object classification for automated surveillance. In European Conference on Computer Vision (pp. 343-357). Springer, Berlin, Heidelberg.

Jia, Y., Shelhamer, E., Donahue, J., Karayev, S., Long, J., Girshick, R., ... \& Darrell, T. (2014,

540 November). Caffe: Convolutional architecture for fast feature embedding. In Proceedings of the 22nd ACM international conference on Multimedia (pp. 675-678). ACM.

Joly, A., Goëau, H., Glotin, H., Spampinato, C., Bonnet, P., Vellinga, W. P., ... \& Müller, H. (2016, September). LifeCLEF 2016: multimedia life species identification challenges. In International Conference of the Cross-Language Evaluation Forum for European Languages (pp. 286-310).

545 Springer International Publishing.

Krizhevsky, A., Sutskever, I., \& Hinton, G. E. (2012). Imagenet classification with deep convolutional neural networks. InAdvances in neural information processing systems (pp. 10971105).

Krueck, N. C., Ahmadia, G. N., Possingham, H. P., Riginos, C., Treml, E. A., \& Mumby, P. J. 550 (2017). Marine reserve targets to sustain and rebuild unregulated fisheries. PLoS biology, 15(1), e2000537.

Kulbicki, M., Parravicini, V., Bellwood, D. R., Arias-Gonzàlez, E., Chabanet, P., Floeter, S. R., ... \& Mouillot, D. (2013). Global biogeography of reef fishes: a hierarchical quantitative delineation of regions.PLoS One,8(12), e81847.

555 Langlois, T.J., Harvey, E.S., Fitzpatrick, B., Meeuwig, J., Shedrawi, G. \& Watson, D. (2010). Costefficient sampling of fish assemblages: comparison of baited video sta=tions and diver video transects. Aquat. Biol., 9, 155-168.

LeCun, Y., Bengio, Y., \& Hinton, G. (2015). Deep learning. nature,521(7553), 436.

Levi, D. M. (2008). Crowding-An essential bottleneck for object recognition: A mini-review.

560 Vision research, 48(5), 635-654.

Li, X., Shang, M., Qin, H., \& Chen, L. (2015, October). Fast accurate fish detection and recognition of underwater images with fast r-cnn. In OCEANS'15 MTS/IEEE Washington (pp. 1-5). IEEE.

Lowe, D. G. (1999). Object recognition from local scale-invariant features. In Computer vision, 565 1999. The proceedings of the seventh IEEE international conference on (Vol. 2, pp. 1150-1157). Ieee.

Mallet, D., \& Pelletier, D. (2014). Underwater video techniques for observing coastal marine biodiversity: a review of sixty years of publications (1952-2012). Fisheries Research, 154, 44-62.

Matabos, M., Hoeberechts, M., Doya, C., Aguzzi, J., Nephin, J., Reimchen, T. E., ... \&

570 Fernandez-Arcaya, U. (2017). Expert, Crowd, Students or Algorithm: who holds the key to deep-sea imagery 'big data'processing?.Methods in Ecology and Evolution.

Mouillot, D., Villéger, S., Parravicini, V., Kulbicki, M., Arias-González, J. E., Bender, M., ... \& Bellwood, D. R. (2014). Functional over-redundancy and high functional vulnerability in global fish faunas on tropical reefs. Proceedings of the National Academy of Sciences, 111(38), 13757-13762.

575 Pandolfi, J. M., Bradbury, R. H., Sala, E., Hughes, T. P., Bjorndal, K. A., Cooke, R. G., \& Warner, R. R. (2003). Global trajectories of the long-term decline of coral reef ecosystems. Science, 301(5635), 955-958.

Pelletier, D., Leleu, K., Mou-Tham, G., Guillemot, N. \& Chabanet, P. (1/2011). Comparison of visual census and high definition video transects for monitoring coral reef fish assemblages. Fish.

580 Res., 107, 84-93.

Price Tack, J. L. et al. 2016. AnimalFinder: A semi-automated system for animal detection in timelapse camera trap images. - Ecol. Inform. 36: 145-151.

Robinson, J. P., Williams, I. D., Edwards, A. M., McPherson, J., Yeager, L., Vigliola, L., \& Baum, J. K. (2017). Fishing degrades size structure of coral reef fish communities. Global change biology, 585 23(3), 1009-1022.

Rogers, A., Blanchard, J. L., \& Mumby, P. J. (2017). Fisheries productivity under progressive coral reef degradation. Journal of Applied Ecology.

Sale, P. F., \& Sharp, B. J. (1983). Correction for bias in visual transect censuses of coral reef fishes. 
Draft Version - Accepted in Elsevier Ecological Informatics the $3^{\text {th }}$ of September 2018

Coral reefs, 2(1), 37-42.

590 Schmidhuber, J. (2015). Deep learning in neural networks: An overview.Neural networks,61, 85117

Scott, A., \& Dixson, D. L. (2016, May). Reef fishes can recognize bleached habitat during settlement: sea anemone bleaching alters anemonefish host selection. In Proc. R. Soc. B (Vol. 283, No. 1831, p. 20152694). The Royal Society

595 Shortis, M. R., Ravanbakhsh, M., Shafait, F., \& Mian, A. (2016). Progress in the automated identification, measurement, and counting of fish in underwater image sequences. Marine Technology Society Journal, 50(1), 4-16.

Siddiqui, S. A., Salman, A., Malik, M. I., Shafait, F., Mian, A., Shortis, M. R., \& Harvey, E. S. (2017). Automatic fish species classification in underwater videos: exploiting pre-trained deep

600 neural network models to compensate for limited labelled data. ICES Journal of Marine Science, fsx 109 .

Spampinato, C., Giordano, D., Di Salvo, R., Chen-Burger, Y. H. J., Fisher, R. B., \& Nadarajan, G. (2010, October). Automatic fish classification for underwater species behavior understanding. In Proceedings of the first ACM international workshop on Analysis and retrieval of tracked events

605 and motion in imagery streams (pp. 45-50). ACM.

Srivastava, N., Hinton, G., Krizhevsky, A., Sutskever, I., \& Salakhutdinov, R. (2014). Dropout: A simple way to prevent neural networks from overfitting. The Journal of Machine Learning Research, 15(1), 1929-1958.

Szegedy, C., Liu, W., Jia, Y., Sermanet, P., Reed, S., Anguelov, D. \& Rabinovich, A. (2015). Going

610 deeper with convolutions. InProceedings of the IEEE conference on computer vision and pattern recognition (pp. 1-9).

Taquet, M., \& Diringer, A. (2007). Poissons de l'océan Indien et de la mer Rouge. Editions Quae.

Thresher, R. E., \& Gunn, J. S. (1986). Comparative analysis of visual census techniques for highly mobile, reef-associated piscivores (Carangidae). Environmental Biology of Fishes, 17(2), 93-116.

615 Villon, S., Chaumont, M., Subsol, G., Villéger, S., Claverie, T., \& Mouillot, D. (2016, October). Coral reef fish detection and recognition in underwater videos by supervised machine learning: Comparison between Deep Learning and HOG+ SVM methods. In International Conference on Advanced Concepts for Intelligent Vision Systems (pp. 160-171). Springer International Publishing. Watson, D.L., Harvey, E.S., Anderson, M.J. \& Kendrick, G.A. (12/2005). A comparison of

620 temperate reef fish assemblages recorded by three underwater stereo-video techniques. Mar. Biol., $148,415-425$

Watson, D.L. \& Harvey, E.S. (2007). Behaviour of temperate and sub-tropical reef fishes towards a stationary SCUBA diver. Mar. Freshw. Behav. Physiol., 40, 85-103

Weinstein, B. G. 2015. MotionMeerkat: Integrating motion video detection and ecological monitoring (S Dray, Ed.). - Methods Ecol. Evol. 6: 357-362.

Willis, T. J., \& Babcock, R. C. (2000). A baited underwater video system for the determination of relative density of carnivorous reef fish. Marine and Freshwater research, 51(8), 755-763.

Willis, T. J. (2001). Visual census methods underestimate density and diversity of cryptic reef fishes. Journal of Fish Biology, 59(5), 1408-1411.

630

https://github.com/NVIDIA/DIGITS/blob/master/digits/standard-networks/caffe/googlenet.prototxt 2018 
Draft Version - Accepted in Elsevier Ecological Informatics the $3^{\text {th }}$ of September 2018

\section{SUPPLEMENTARY TABLES}

Table S1. Raw fish thumbnails training dataset

645

$\begin{array}{cc}\text { Classes } & \text { Number of thumbnails } \\ \text { Abudefduf sparoides } & 1241 \\ \text { Abudefduf vaigiensis } & 5674 \\ \text { Chaetodon trifascialis } & 1456 \\ \text { Chromis weberi } & 3576 \\ \text { Dascyllus carneus } & 2276 \\ \text { Lutjanus kasmira } & 1652 \\ \text { Monotaxis grandoculis } & 1239 \\ \text { Myripristis botche } & 1264 \\ \text { Naso elegans } & 2068 \\ \text { Mulloidichtys vanicolensis } & 1264 \\ \text { Naso vlamingii } & 1789 \\ \text { Nemateleotris magnifica } & 1189 \\ \text { Odonus niger } & 2986 \\ \text { Plectroglyphidodon lacrymatus } & 652 \\ \text { Pomacentrus sulfureus } & 5176 \\ \text { Preocaesio tile } & 3088 \\ \text { Pygoplytes diacanthus } & 1106 \\ \text { Thalassoma hardwicke } & 1579 \\ \text { Zanclus cornutus } & 1886 \\ \text { Zebrasoma scopas } & 1835\end{array}$


Table S2. The four thumbnails datasets used to train the four models, with for each the number of thumbnails per class in the training datasets, with class "environment" gathering thumbnails of water and substrate (sand, corals) while "Part of fish" gathers all thumbnails of half of a fish individual and the "part of species" classes contain thumbnails of half of individuals for each species.

\begin{tabular}{|c|c|c|c|c|}
\hline Species & $\begin{array}{l}\text { Only whole fish } \\
\text { (T1) }\end{array}$ & $\begin{array}{l}\text { Whole fish + "Part of } \\
\text { fish" (T2) }\end{array}$ & $\begin{array}{l}\text { Whole fish + Environment + } \\
\text { "Part of fish" (T3) }\end{array}$ & $\begin{array}{c}\text { Whole fish + environment + "Part of } \\
\text { species" (T4) }\end{array}$ \\
\hline Abudefduf sparoides & 2482 & 2482 & 2482 & 2482 \\
\hline Abudefduf vaigiensis & 11328 & 11328 & 11328 & 11328 \\
\hline Chaetodon trifascialis & 2912 & 2912 & 2912 & 2912 \\
\hline Chromis weberi & 7152 & 7152 & 7152 & 7152 \\
\hline Dascyllus carneus & 4552 & 4552 & 4552 & 4552 \\
\hline Lutjanus kasmira & 3300 & 3300 & 3300 & 3300 \\
\hline Monotaxis grandoculis & 2478 & 2478 & 2478 & 2478 \\
\hline $\begin{array}{c}\text { Mulloidichtys } \\
\text { vanicolensis }\end{array}$ & 2528 & 2528 & 2528 & 2528 \\
\hline Myripristis botche & 2528 & 2528 & 2528 & 2528 \\
\hline Naso elegans & 4138 & 4138 & 4138 & 4138 \\
\hline Naso vlamingii & 3578 & 3578 & 3578 & 3578 \\
\hline Nemateleotris magnifica & 2378 & 2378 & 2378 & 2378 \\
\hline Odonus niger & 5972 & 5972 & 5972 & 5972 \\
\hline $\begin{array}{l}\text { Plectroglyphidodon } \\
\text { lacrymatus }\end{array}$ & 1304 & 1304 & 1304 & 1304 \\
\hline Pomacentrus sulfureus & 10352 & 10352 & 10352 & 10352 \\
\hline Preocaesio tile & 6176 & 6176 & 6176 & 6176 \\
\hline Pygoplytes diacanthus & 2212 & 2212 & 2212 & 2212 \\
\hline Thalassoma hardwicke & 3158 & 3158 & 3158 & 3158 \\
\hline Zanclus cornutus & 3772 & 3772 & 3772 & 3772 \\
\hline Zebrasoma scopas & 3670 & 3670 & 3670 & 3670 \\
\hline $\begin{array}{c}\text { Part of } \\
\text { Abudefduf sparoides }\end{array}$ & & & & 4964 \\
\hline $\begin{array}{c}\text { Part of } \\
\text { Abudefduf vaigiensis }\end{array}$ & & & & 22656 \\
\hline Chaetodon trifascialis & & & & 5824 \\
\hline $\begin{array}{c}\text { Part of } \\
\text { Naso elegans }\end{array}$ & & & & 14304 \\
\hline Part of & & & & 20704 \\
\hline Pomacentrus sulfureus & & & & \\
\hline Part of & & & & 4424 \\
\hline Pygoplites diacanthus & & & & \\
\hline $\begin{array}{l}\text { Part of } \\
\text { Thalassoma hardwicke }\end{array}$ & & & & 6316 \\
\hline $\begin{array}{l}\text { Part of } \\
\text { Palcke }\end{array}$ & & & & 7544 \\
\hline Zanclus cornutus & & & & \\
\hline $\begin{array}{l}\text { Part of } \\
\text { Par }\end{array}$ & & & & 7340 \\
\hline $\begin{array}{l}\text { Zebrasoma scopas } \\
\text { Part of }\end{array}$ & & & & 14034 \\
\hline Chromis weberi & & & & \\
\hline $\begin{array}{c}\text { Part of } \\
\text { Monotaxis grandoculis }\end{array}$ & & & & 4956 \\
\hline $\begin{array}{l}\text { Part of } \\
\text { Plectroglyphidodon }\end{array}$ & & & & 1304 \\
\hline lacrymatus & & & & \\
\hline Part of & & & & 9097 \\
\hline Dascyllus carneus & & & & \\
\hline Part of & & & & 5056 \\
\hline $\begin{array}{l}\text { Myripristis botche } \\
\text { Part of }\end{array}$ & & & & \\
\hline $\begin{array}{c}\text { Part of } \\
\text { Naso vlamingii }\end{array}$ & & & & 7156 \\
\hline $\begin{array}{l}\text { Naso vlamingli } \\
\text { Part of }\end{array}$ & & & & 4744 \\
\hline Nemateleotris magnifica & & & & \\
\hline Part of & & & & 11944 \\
\hline Odonus niger & & & & \\
\hline Part of & & & & 12352 \\
\hline Pterocaesio tile & & & & \\
\hline $\begin{array}{l}\text { Part of } \\
\text { Mulloidichtys } \\
\text { vanicolensis }\end{array}$ & & & & 7528 \\
\hline Part of Fish & & 521555 & 521555 & \\
\hline Environment & & & 862174 & 862174 \\
\hline
\end{tabular}


Table S3: Number of thumbnails of each fish species present in test datasets used in this study

660

\begin{tabular}{ccc}
\hline Class & $\begin{array}{c}\text { Dataset for testing models } \\
\text { performance }\end{array}$ & $\begin{array}{c}\text { Dataset for testing model } \\
\text { performance vs human } \\
\text { performance }\end{array}$ \\
Abudefduf sparoides & 103 & 88 \\
Abudefduf vaigiensis & 59 & 47 \\
Chaetodon trifascialis & 208 & 146 \\
Chromis weberi & 269 & \\
Dascyllus carneus & 269 & \\
Monotaxis grandoculis & 72 & \\
Myripristis botche & 20 & \\
Naso elegans & 189 & \\
Naso vlamingii & 358 & \\
Nemateleotris magnifica & 246 & \\
Odonus niger & 176 & 465 \\
Plectroglyphidodon lacrymatus & 150 & \\
Pomacentrus sulfureus & 1567 & 35 \\
Pterocaesio tile & 215 & 73 \\
Pygoplytes diacanthus & 39 & \\
Thalassoma hardwicke & 111 & \\
Zanclus cornutus & 64 & \\
Zebrasoma scopas & 184 & \\
Total & 4405 & \\
\hline
\end{tabular}


Table S4. Performance of CNN model trained with T4 thumbnails set to identify nine fish species with no post processing; species are identified in columns and rows refer to whole fish and parts of fish present in the training dataset.

665 Part of species X means that some individual were recognized as part of a fish species.

Only percentages of over $1 \%$ are shown.

\begin{tabular}{|c|c|c|c|c|c|c|c|c|c|}
\hline Species & $\begin{array}{l}\text { A.sparo } \\
\text { ides }\end{array}$ & A.vaigiensis & C.trifascialis & N.elegans & P.sulfureus & P.diacanthus & T.hardwicke & Z.cornutus & Z.scopas \\
\hline A. sparoides & 82.8 & & & & & & & & \\
\hline A.vaigiensis & 1.1 & 80.0 & & & & & & & \\
\hline C. trifascialis & & & 85.1 & & & & & & \\
\hline C. weberi & & & & & & & 1.1 & & \\
\hline N. elegans & & & & 95.1 & & & & & 3.9 \\
\hline P. sulfureus & & & & & 73.8 & 2.6 & & & \\
\hline P. diacanthus & & & & & & & 86.8 & & \\
\hline T. hardwicke & & & & & & & & 87.3 & \\
\hline Z. cornutus & & & & & & & & & 89.0 \\
\hline Z. scopas & & & & & & & & & 92.7 \\
\hline $\begin{array}{l}\text { Part of } A \text {. } \\
\text { sparoides }\end{array}$ & 6.0 & & & & & & & & \\
\hline $\begin{array}{l}\text { Part of } A \text {. } \\
\text { vaigiensis }\end{array}$ & 1.0 & 9.1 & & & & & & & \\
\hline $\begin{array}{l}\text { Part of } C \\
\text { trifascialis }\end{array}$ & & & 2.6 & & & & & & \\
\hline Part of $N$. elegans & & & & 1.6 & & & & & \\
\hline $\begin{array}{l}\text { Part of } P \\
\text { sulfureus }\end{array}$ & & & 1.1 & & 4.3 & & & & \\
\hline $\begin{array}{l}\text { Part of } P \text {. } \\
\text { diacanthus }\end{array}$ & & & & & & & & & \\
\hline $\begin{array}{l}\text { Part of } T \text {. } \\
\text { hardwicke }\end{array}$ & & & & & & & 2.6 & & \\
\hline $\begin{array}{l}\text { Part of } Z \text {. } \\
\text { cornutus }\end{array}$ & & & & & & & & 6.2 & \\
\hline \multicolumn{10}{|l|}{ Part of Z. scopas } \\
\hline Environment & 8.0 & 10.9 & 9.5 & 2.2 & 20.9 & 7.9 & 9.2 & 4.6 & 2.8 \\
\hline
\end{tabular}


Table S5. Performance of our final CNN model to identify 9 fish species.

670 Raw model output was post-processed with following decision rule: outputs " part of species X" and "species X" are considered the same (i.e., the results of A. sparoides and part of A. sparoides are added together); species are in columns with rows indicating the percentage of good identification for each species and only values over $1 \%$ are shown.

675

\begin{tabular}{|c|c|c|c|c|c|c|c|c|c|}
\hline Species & $\begin{array}{l}\text { A. } \\
\text { sparoid }\end{array}$ & $\begin{array}{l}\text { A. } \\
\text { s vaigiensis }\end{array}$ & $\begin{array}{l}\text { C. } \\
\text { trifascialis }\end{array}$ & N.elegans & P.sulfureus & P.diacanthus & T.hardwicke & Z.cornutus & Z.scopas \\
\hline \multicolumn{10}{|c|}{ A. sparoides 89.0} \\
\hline A. vaigiensis & 2.1 & 89.1 & & & & & & & \\
\hline$C$. & & & 97.7 & & & & & & \\
\hline \multicolumn{10}{|l|}{ trifascialis } \\
\hline C. weberi & & & & & & & 1.1 & & \\
\hline D. caruleus & & & & & & & & & 3.9 \\
\hline N. elegans & & & & 95.7 & & & & & \\
\hline P. sulfureus & & & 3.1 & & 78.1 & 2.6 & & & \\
\hline P. diacanthus & & & & & & 86.8 & & & \\
\hline T. hardwicke & & & & & & 89.4 & & & \\
\hline Z.cornutus & & & & & & & & 95.2 & \\
\hline Z. scopas & & & & & & & & & 92.7 \\
\hline Environment & 8.0 & 10.9 & 9.5 & 2.1 & 20.9 & 7.9 & 9.2 & 4.6 & 2.8 \\
\hline
\end{tabular}




\section{SUPPLEMENTARY FIGURES}

680 Supplementary Figure 1. Screenshot of the online application used for testing human performance in identifying fish on thumbnails. Picture of fish to identify is displayed on the left part. Name for species should be typed in the bottom text bar (with auto-completion). The help box with examples of the 9 species to identify is visible on the right.

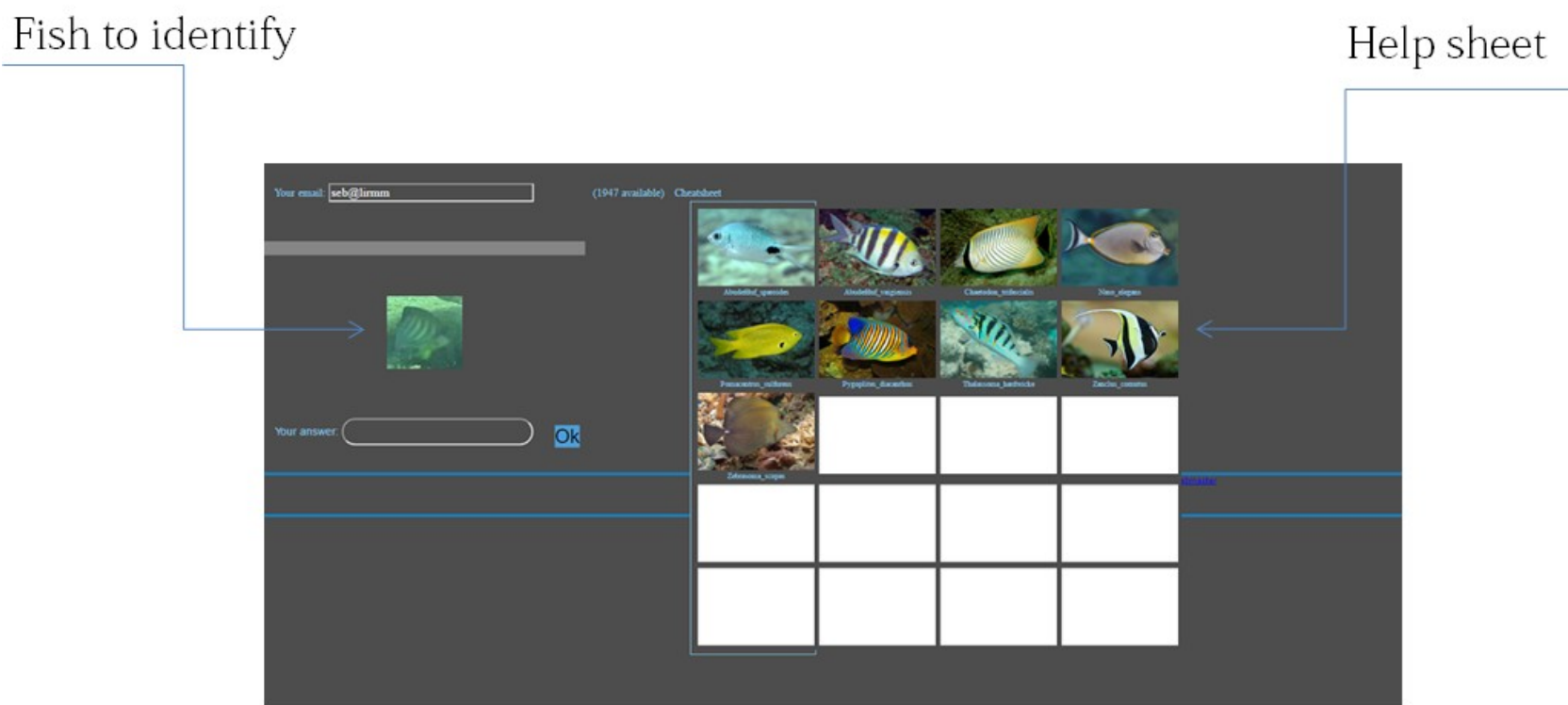

